\title{
Manifestações Emocionais do Terapeuta Durante as Sessões: Por que Arriscar-se e Quais Benefícios Esperar?
}

\author{
Olívia Rodrigues da Cunha ${ }^{1}$ \\ Luc Vandenberghe ${ }^{1}$ \\ ${ }^{1}$ Pontifícia Universidade Católica de Goiás, GO, Brasil. $\quad$ IPontifícia Universidade Católica de Goiás, GO, Brasil.
}

Resumo: A teorização contemporânea enfatiza o envolvimento emocional do terapeuta no relacionamento terapêutico. O objetivo desse estudo é compreender como esse envolvimento se dá na prática clínica e por que terapeutas escolham esse caminho. Foi desenvolvido um estudo a partir de entrevistas a 14 terapeutas, com perguntas sobre como utilizam suas emoções em sessão e quais benefícios visam com essa ação. A análise e categorização dos dados encontrados foram pautadas nos preceitos da Grounded Theory Analysis. Os resultados sugerem que terapeutas expõem suas emoções em sessão com objetivo de diagnóstico e como intervenção terapêutica, promovendo comportamentos alvo e maior consciência de processos interpessoais no cliente. Para o terapeuta, trabalhar com suas emoções pode acarretar em transformações tanto pessoais quanto profissionais. Em uma relação emocionalmente próxima, aberta e genuína no consultório, não só o cliente, mas também o terapeuta é transformado. Assim, a mudança que ocorre no processo terapêutico não deve ser pensada como um processo unilateral.

Palavras-chave: Pessoa do Terapeuta, Grounded Theory Analysis, Relacionamento Terapêutico, Envolvimento Emocional.

\section{Emotional Manifestations of the Therapist During Sessions: Why Take Risks and What Benefits to Expect?}

\begin{abstract}
Contemporary theory emphasizes the therapist's emotional involvement in the relationship with the client. The aim of this study is to explore how this emotional involvement happens in practice and why therapists choose this option. A study questioned 14 therapists in semi-structured interviews about how they use their emotions and what gains they attribute to this intervention. The analysis and categorization of the data obtained followed the principles of Grounded Theory Analysis. The results suggest that the disclosure of the therapist's emotions in session can help diagnosis and serve as a tool for therapeutic progress, including development of client target behaviors, and increased interpersonal process awareness. For therapists, working with their emotions can promote both personal and professional change. Not only the client, but the therapist as well, is transformed with each open and genuine close relationship in the therapist's office. As such, the change in treatment should not be thought of as a one-way process.
\end{abstract}

Keywords: The Person of the Therapist, Grounded Theory Analysis, Therapeutic Relationship, Emotional Involvement. 


\title{
Manifestaciones Emocionales del Terapeuta Durante las Sesiones: ¿Por qué Arriesgarse y qué Beneficios Esperar?
}

\begin{abstract}
Resumen: La teorización contemporánea enfatiza la implicación emocional del terapeuta en la relación terapéutica. El objetivo de este estudio es comprender cómo esta implicación se da en la práctica clínica y por qué los terapeutas eligen ese camino. Se desarrolló un estudio a partir de entrevistas a 14 terapeutas, con preguntas sobre cómo utilizan sus emociones en sesión y cuáles beneficios visan con esa acción. El análisis y categorización de los datos encontrados se basó en los preceptos de Grounded Theory Analysis. Los resultados sugieren que los terapeutas exponen sus emociones en sesión con objetivo de diagnóstico y como intervención terapéutica, promoviendo comportamientos objetivo y mayor conciencia de procesos interpersonales en el cliente. Para el terapeuta, trabajar con sus emociones puede acarrear en transformaciones tanto personales como profesionales. En una relación emocionalmente cercana, abierta y genuina en el consultorio, no sólo el cliente, pero también el terapeuta es transformado. Así, el cambio que ocurre en el proceso terapéutico no debe ser pensado como un proceso unilateral.
\end{abstract}

Palabras clave: Persona del Terapeuta, Grounded Theory Analysis, Relación Terapéutica, Compromiso Emocional.

Nas últimas décadas, a literatura sobre psicoterapia enfatiza que o trabalho na clínica deve se pautar em uma relação de igualdade e na abertura bidirecional à mudança. Conceder abertura plena para os direitos do cliente na sessão e negociar de forma transparente e equitativa o poder no relacionamento, não é mais visto como somente uma questão de ética, mas um ingrediente importante para o processo curativo (Linehan, 1988; Tsai, Kohlenberg, Kanter, Holman, \& Loudon, 2012; Fideles, \& Vandenberghe, 2014). A questão investigada nessa pesquisa está ligada a um aspecto da relação de igualdade e abertura mútua, a saber, a disposição do terapeuta de trabalhar de forma transparente com suas próprias emoções.

A literatura tem instruído como os clínicos devem relacionar-se com seus clientes, baseada em princípios teóricos e traz pesquisas sobre como uma relação terapêutica deve ser conduzida (por exemplo: Goldfried, Burckell \& Eubanks-Carter, 2003; Hill et al., 1988; Tsai et al., 2012). O presente estudo é uma contribuição numa sequência de trabalhos à contramão dessa tendência. Em vez de propor regras a respeito do comportamento do terapeuta, procura-se dar voz à vivência do profissional. Como é para o terapeuta, usar como ferramenta de trabalho sua relação com outra pessoa - algo tão particular e imbuído de sentimentos e significados pessoais? Ao valorizar a van- tagem epistêmica da pessoa que vive o fenômeno no seu dia a dia, essa linha de pesquisa procura contrabalancear o viés instrucional da literatura. Resumimos alguns resultados em seguida.

Os resultados de Silvestre e Vandenberghe (2014) relacionam a adesão do cliente e a produtividade do processo com uma interação pessoal e aberta na sessão. Apontam também os perigos relacionados à abertura emocional do terapeuta. No estudo de Vieira e Vandenberghe (2017), terapeutas relatam expor suas vivências pessoais com uma variedade de intenções terapêuticas, como favorecer alguma mudança na vida do cliente, apoiar as tentativas do cliente de expressar-se, ou ainda, intensificar o vínculo terapêutico.

Uma série de pesquisas baseadas em estudos de caso mostra que, ao aceitar serem tocados pelo cliente, terapeutas conseguem observar como o cliente se relaciona com outras pessoas e a partir disso, conseguem trabalhar diretamente as formas pelas quais o cliente tenta suprir suas necessidades numa relação interpessoal (Santo, \& Vandenberghe, 2015; Vandenberghe, \& Silveira, 2013). Para clientes com dificuldades em construir laços de intimidade ou problemas em lidar com a proximidade afetiva, construir com o terapeuta uma relação genuína e transparente, pode acarretar progressos clínicos importantes (Vandenberghe, Nasser, \& Silva, 2010). 
Estar atento às próprias emoções ajuda o terapeuta comportamental a identificar as contingências que estão atuando entre ele e o cliente e a usar essa informação para aprimorar sua análise funcional (Silvestre, \& Vandenberghe, 2008). Em dois estudos de caso (Santo, \& Vandenberghe, 2015), o envolvimento emocional da terapeuta com o cliente permitiu uma atuação clínica focada. A profissional contou do impacto que os comportamentos dos clientes tiveram sobre ela, para que eles pudessem entender como a afetaram. Foi um primeiro passo para que aprendessem a ver como afetam as pessoas com quem interagem e trouxe elementos para que eles começassem a construir relações mais flexíveis e saudáveis.

Similarmente, Silvestre e Vandenberghe (2008) analisaram momentos em que uma terapeuta compartilhou seu sentimento de ter sido invalidada durante as sessões de terapia de casal. Essa revelação da terapeuta permitiu aos clientes uma conexão com o sofrimento causado pelas maneiras em que o marido invalidava pessoas próximas a ele. A revelação ofereceu um modelo para a esposa aprender a mostrar ao seu marido como ele a afetava. Assim, a exposição das emoções da terapeuta oportunizou ao casal experimentar novas formas de se relacionar que viria a melhorar os problemas que os levaram para a terapia.

Um cliente que raramente importava-se com os outros, e era visto como egocêntrico ou indiferente, mostrou, num dado momento da terapia, interesse nos sentimentos e valores pessoais da terapeuta. Ao responder honestamente, a terapeuta apoiou o desenvolvimento de um repertório interpessoal incipiente desse cliente que proporcionaria uma diferença relevante na sua vida (Vandenberghe, Coppede, $\&$ Kohlenberg, 2006). O estudo de caso de Machado e Vandenberghe (2014) detalhou como uma terapeuta usava suas emoções na interação com uma cliente borderline para superar entraves específicos no processo terapêutico, como quando padrões de fuga e esquiva da cliente dificultavam as intervenções, quando o diálogo terapêutico não alcançava a cliente em um nível emocional e quando problemas interpessoais inerentes à personalidade borderline, interferiam no vínculo terapêutico.

Percebe-se que terapeutas colocam o uso das suas emoções diretamente a serviço das metas terapêuticas. Porém, usar os sentimentos na sessão pode também criar impasses na terapia e gerar sofrimento para o clínico. Abrir-se genuinamente para um cliente com problemas interpessoais graves pode se tornar doloroso. Fugir das dificuldades, assumir uma atitude neutra e fria ou elaborar explicações racionais que afastam as implicações pessoais do que ocorre no relacionamento com o cliente seria mais cômodo, mas limitaria o alcance da terapia. As dificuldades abrem, muitas vezes, novas possibilidades para o tratamento (Machado, \& Vandenberghe, 2014; Vandenberghe, \& Silveira, 2013).

O profissional pode transformar os impasses em oportunidades terapêuticas ao analisar de forma aberta seu envolvimento na relação (Cunha, \& Vandenberghe, 2016). No estudo de Oliveira e Vandenberghe (2009), terapeutas relataram que, muitas vezes, a dor que pode decorrer do envolvimento genuíno no relacionamento com o cliente, serve de norte para rever e aprofundar a compreensão dos problemas do mesmo. Ao se vulnerabilizar, o clínico pode se tornar mais apto no momento de fazer uma intervenção que não seja baseada num entendimento teórico do problema, mas numa compreensão emocional verídica. Ademais, os terapeutas relataram aprendizados para a vida fora do consultório, como saber lidar com o comportamento difícil de terceiros, serem mais tolerantes, e desenvolveram uma melhor compreensão da própria angústia.

Os resultados acima resumidos mostram que terapeutas têm consciência dos benefícios e dos custos do seu envolvimento em um relacionamento genuíno com o cliente. Em alguns momentos, os estudos se complementam, mas ainda oferecem um panorama fragmentado. Uma teoria substancial acerca da manifestação emocional do terapeuta em sessão precisa ser claramente ancorada numa reflexão sobre seus objetivos e efeitos. O presente estudo pretende avançar na análise de como os terapeutas na prática clínica compreendem suas intenções ao lançar mão de suas emoções e sobre as repercussões das mesmas no sentido mais amplo.

\section{Método}

\section{Participantes}

Participaram da pesquisa 14 psicólogos. Sendo oito do sexo feminino e seis do sexo masculino. Eles tinham em média 7,6 anos de experiência clí- 
nica, variando entre dois a 20 anos e trabalhando com distintos enfoques teóricos. Foram encontrados através da divulgação de informações sucintas sobre a pesquisa em páginas profissionais nas redes sociais selecionadas, e através de convite a psicólogos que possuíssem familiaridade com o foco da pesquisa (utilização das suas emoções em seus atendimentos clínicos).

Os terapeutas que participaram da pesquisa foram escolhidos de acordo com os seguintes critérios: a) ser psicólogo com credenciamento ativo junto a um Conselho Regional de Psicologia; b) relatar usar suas emoções em atendimentos clínicos e c) ter no mínimo dois anos de experiência clínica. Pretendeu-se incluir somente profissionais com perfil clínico e que atribuem relevância clínica no uso das suas emoções. Foram excluídos os terapeutas cuja ênfase de trabalho não fosse a área clínica. $\mathrm{O}$ critério $\mathrm{b}$ foi inserido para atender ao princípio de amostragem teórica (Charmaz, 2006), privilegiando participantes aptos e dispostos a oferecer informação que ajuda a responder à questão da pesquisa.

\section{Materiais}

As entrevistas sondaram as situações que antecedem ou provocam a utilização das emoções; a forma como os terapeutas as manifestam; as intenções em utilizá-las; quais as consequências acarretadas pela expressão das emoções; e as impressões que ficaram ao terapeuta. Cada entrevista começou com a solicitação que o participante escolhesse exemplos de situações relevantes e que nomeasse as emoções presentes nos exemplos. Conforme as respostas eram dadas, a pesquisadora formulava novas perguntas com intuito de esclarecer e aprofundar algum ponto. A coleta de dados seguiu o método da Grounded Theory Analyis, na sua forma modificada proposta por Charmaz (2006).

\section{Procedimento}

As entrevistas tiveram duração média de 46 minutos. A mais curta foi de 28 minutos, e a mais longa de 1 hora e 8 minutos. Elas foram realizadas no consultório dos terapeutas, via Skype, caso assim fosse acordado, ou no local de escolha dos participantes, desde que respeitasse as condições necessárias de privacidade. As entrevistas foram gravadas e transcritas pela primeira autora, de modo que ape- nas ela e seu orientador tiveram acesso ao material para análise dos dados.

Ao escolher a Grounded Theory Analysis como método de coleta e análise de dados, valeu-se durante toda a pesquisa do agnosticismo teórico, uma postura que consiste na recusa da pesquisadora de ajustar sua interpretação precocemente a uma posição teórica já articulada ou a estudos realizados na área (Henwood \& Pidgeon, 2003). Noções já desenvolvidas em estudos anteriores foram resgatadas como conceitos sensibilizadores. A noção de "conceitos sensibilizadores" denota convicções e ideias advindas da formação ou experiência do pesquisador. São usados para direcionar a atenção dos pesquisadores para elementos potencialmente importantes, mas são também contidos, a fim de evitar que a nova pesquisa seja enviesada e limitada pelas ideias já elaboradas (Blumer, 1969).

Aqui, o termo "agnosticismo" não é usado no sentido filosófico, mas epistemológico, referindo-se à suspensão de preferências teóricas (Charmaz, 2006). O que sustenta essa postura é a preocupação de construir uma narrativa que seja fiel às vivências analisadas. Elementos provenientes de diferentes teorias podem se tornar relevantes na análise. Porém, a leitura dos dados pela lente de conceitos consagrados pode cegar aspectos que não cabem nesses conceitos. A adesão a um modelo específico tem a tendência de estreitar e normalizar os resultados produzidos pela pesquisa, adequando-os à teoria preexistente.

Charmaz (2006) acrescenta que, mesmo não sendo possível conduzir a pesquisa com uma mente vazia, nada impede que a pesquisadora tenha uma mente aberta. Ainda que os pesquisadores possuam interesses, são necessárias comparações constantes desses com os resultados obtidos e são os dados que direcionam a análise (Lyn, \& Morse, 2013). Para efetuar essas comparações constantes, é necessário tornar explícitos os conceitos sensibilizadores dos pesquisadores. O uso consciente dos conceitos pode ajudar a aguçar a sensibilidade dos pesquisadores, e preveni-los de forçar inadvertidamente os conceitos nos dados (Glaser, 1998).

Assim, a primeira autora trouxe sua crença numa relação terapêutica de cooperação não hierarquizada, de que uma relação intensa e calorosa pode desencadear melhoras na vida do cliente. O segundo autor, entrou com seu interesse em compreender os efeitos da pessoa do terapeuta no processo clínico e trouxe, de pesquisas anteriores, as ideias de que terapeu- 
tas possuem consciência dos benefícios e dos custos do seu envolvimento pessoal na relação (Oliveira, \& Vandenberghe, 2009), e que fazem uso estratégico de revelações sobre si (Vieira, \& Vandenberghe, 2017). Os conceitos sensibilizadores foram elencados no início da pesquisa e usados de maneira crítica na elaboração de questionamentos sobre os tópicos da pesquisa e na compreensão do sentido dos dados encontrados.

A primeira autora conduziu as entrevistas e preparou as transcrições. Os dois autores colaboraram na análise interpretativa. Foi feita uma leitura analítica do material e um delineamento de unidades de sentido. Foram criados códigos que sintetizassem e explicassem essas unidades. A codificação aberta induz a estudar os dados rigorosamente e a começar a conceituar as ideias (Charmaz, 2006). Esta análise inicial constitui um recurso descritivo que permite reconhecer quando os sentidos se repetiam no texto, qualificando-os com o mesmo código, sendo que esses códigos foram alterados e melhorados ao longo das análises. À medida que os códigos iam sendo criados, poderiam influenciar na análise das entrevistas posteriores e sugerir novas questões para as entrevistas seguintes.

Em seguida, os dados passaram por uma codificação focalizada que permitiu separar, classificar e sintetizar maiores quantidades de dados. Foi desenvolvido um trabalho de comparação contínua entre os dados de cada entrevista, das outras entrevistas, entre os códigos emergentes e os dados brutos. Através dessas comparações, categorias foram construídas. Essas organizam códigos a partir das suas similaridades e diferenças. As categorias abarcam temas comuns a vários códigos de uma forma mais genérica (Charmaz, 2006). A grande quantidade de categorias criadas inicialmente foi agrupada em categorias maiores que nortearam a redação dos resultados. Assim, os resultados serão apresentados partindo das categorias que emergiram da análise dos códigos que serão exemplificados por fragmentos retirados das entrevistas.

\section{Resultados}

Dois grandes eixos emergiram da análise. Serão identificados como "objetivos terapêuticos" e "consequências para o terapeuta" envolvendo o uso das emoções do terapeuta no atendimento clínico (veja Quadro).

Terapeutas usam suas emoções para objetivos clínicos. Eles procuram não as expor a não ser por motivos claros e bem definidos. A exposição de emoções pode introduzir novas perspectivas interpessoais que podem contribuir para o processo clínico. Apesar dessa restrição, o uso das emoções do terapeuta pode trazer ganhos secundários ao terapeuta, tanto para

Quadro

Objetivos e consequências do uso das emoções do terapeuta no atendimento.

\begin{tabular}{|ll|}
\hline Categorias & \multicolumn{1}{c|}{ Terapeutas que contribuíram } \\
\hline Objetivos terapêuticos & \\
Acessar problemas clinicamente relevantes, auxiliar no & (11) $\mathrm{T} 1, \mathrm{~T} 3, \mathrm{~T} 4, \mathrm{~T} 5, \mathrm{~T} 6, \mathrm{~T} 7, \mathrm{~T} 8, \mathrm{~T} 9, \mathrm{~T} 10, \mathrm{~T} 11, \mathrm{~T} 12$, \\
diagnóstico e na formulação do caso & $\mathrm{T} 13$ \\
Evocar novos comportamentos & (3) $\mathrm{T} 1, \mathrm{~T} 4, \mathrm{~T} 8$ \\
Reforçar comportamentos alvo e enfraquecer & (6) $\mathrm{T} 1, \mathrm{~T} 2, \mathrm{~T} 3, \mathrm{~T} 7, \mathrm{~T} 11, \mathrm{~T} 13$ \\
comportamentos problema & (5) $\mathrm{T} 5, \mathrm{~T} 6, \mathrm{~T} 7, \mathrm{~T} 8, \mathrm{~T} 14$ \\
Oferecer interpretações relacionais & (4) $\mathrm{T} 1, \mathrm{~T} 2, \mathrm{~T} 6, \mathrm{~T} 14$ \\
Promover tomada de perspectiva reflexiva da vivência do & \\
outro na interação & (6) $\mathrm{T} 1, \mathrm{~T} 2, \mathrm{~T} 5, \mathrm{~T} 9, \mathrm{~T} 10, \mathrm{~T} 13$ \\
Promover tomada de perspectiva contextual da própria & \\
experiência na interação. & (7) $\mathrm{T} 1, \mathrm{~T} 4, \mathrm{~T} 6, \mathrm{~T} 7, \mathrm{~T} 8, \mathrm{~T} 9, \mathrm{~T} 10$ \\
Propor modelos para novos comportamentos & (2) $\mathrm{T} 3, \mathrm{~T} 8$ \\
Consequências para o terapeuta & (4) $\mathrm{T} 2, \mathrm{~T} 3, \mathrm{~T} 8, \mathrm{~T} 11$ \\
Em sua vida pessoal & \\
Em sua vida profissional &
\end{tabular}


sua vida profissional, quanto pessoal, mesmo não sendo este o objetivo.

\section{Acessar problemas, auxiliar no diagnóstico e na formulação de caso}

Terapeutas usam suas emoções para entrar em contato com as dificuldades do cliente:

Atender homem que trabalha em corporação militar e aí ele fala alguma coisa e você sente que ele deveria entrar mais em contato. Você fala da sua emoção e ele chora, por exemplo. Isso eu vejo como um ponto, uma oportunidade, [...] quebrar essa resistência, algum gelo (T9).

Se envolver emocionalmente pode propiciar que os comportamentos clinicamente relevantes advindos de outros ambientes interpessoais na vida do cliente, surjam também no setting terapêutico, onde podem ser trabalhados de forma direta enquanto estão ocorrendo: "Ela falou que percebeu, mas que não entendia o quê na ironia dela me provocava tanta raiva e aí trabalhamos isso em terapia" (T6).

Para trabalhar dessa maneira, o terapeuta deve abrir-se para ser tocado pelo cliente. Essa abertura para o imprevisto é necessária. O que acontecerá no relacionamento será diferente para cada cliente:

Claro, eu me preparo o máximo possível. Mas você vai aprendendo muito na própria relação, por mais que você saiba muita coisa sobre como conduzir uma sessão ou sobre um problema específico. Cada cliente tem seu passo, uma história carregada de sentido. [...] E é nesse encontro que a coisa acontece e é essa pessoa e o que ela traz que eu preciso aprender. Eu me coloco inteira e presente pra a pessoa e é aprendendo com ela e ensinando ela no que eu posso, que a terapia faz sentido de verdade (T3).

Através de uma relação emocional próxima e genuína, o terapeuta ganha acesso ao impacto que o comportamento do cliente causa nas pessoas com quem ele se relaciona fora do espaço terapêutico. Essa proximidade possibilita construir uma melhor compreensão do caso, traz elementos particulares que podem tornar a avaliação e a formulação do caso mais precisa:
Eu comecei a perceber que a verdade mais próxima que eu tenho daquele cliente, de como ele é e funciona em suas relações eram as minhas próprias emoções, esse fluxo da relação é o que eu tenho de mais próximo, de mais verdadeiro ali (T9).

\section{Evocar, reforçar ou enfraquecer comportamentos}

As emoções do terapeuta são utilizadas como recursos:

A expressão emocional do terapeuta, acaba sendo uma própria técnica [...] - da minha parte, ela é utilizada quando eu observo que tem algum fundamento técnico ou que ela pode de alguma maneira ser uma técnica auxiliar para um objetivo terapêutico que eu estou planejando (T4).

A expressão do que o terapeuta sente pode "ajudar a fazer aparecer novas formas do cliente se comportar". Para que a interação na sessão tenha um potencial curativo e não seja uma mera repetição do que ocorre na vida cotidiana do cliente, o terapeuta deve reagir de maneira que difira das respostas que o cliente vinha recebendo em seus outros ambientes: "Eu não entro nesse jogo. [...] A ideia é dar algo diferente do que aquela pessoa vinha recebendo. Me emociono possivelmente igual, mas manejo de outra forma" (T11).

Um comportamento alvo do cliente, ainda muito fraco para ser relevante nos contextos da vida cotidiana do cliente, já pode evocar uma resposta emocional genuína no terapeuta. Expressar essa emoção pode apoiar o desenvolvimento desse comportamento: "Deixar claro pro cliente, entrar em contato com minha própria emoção e expressá-la pro cliente, na tentativa justamente de aumentar o impacto desse reforço" (T1). Esse uso não é restrito a respostas afetivas positivas do terapeuta, mas também inclui emoções tidas como negativas:

Foi o jeito que eu achei na hora de expressar isso, de tentar fazer com que ela respeitasse o compromisso comigo. E mais pra frente, eu vi que ela precisava disso, porque também não tinha 
respeito com os compromissos que fazia com as outras pessoas e aí se sentia sozinha, o que era uma das queixas mais fortes dela, por sinal (T2).

Expressar um impacto doloroso que um comportamento do cliente teve sobre o terapeuta pode permitir ao cliente entrar em contato com a forma em que ele afetou outra pessoa (no caso o terapeuta). É possível, assim, trabalhar sua forma de interagir com outras pessoas:

Tentando falar o quanto aquilo está sendo incômodo pra mim, o quanto está sendo invasivo [...]. Quero ajudá-la, quando é verdade, lógico, mas que está passando de algum limite meu que não pode ser ultrapassado, senão aquela relação vai se perder (T1).

\section{Oferecer interpretações relacionais}

Compartilhar reações emocionais genuínas do terapeuta abre oportunidades para oferecer interpretações relacionais. Expor-se de maneira franca abre espaço para introduzir uma interpretação do que ocorreu na relação terapêutica, e averiguar paralelos com situações vividas nas relações do cliente fora do consultório:

Olha, muito interessante ou muito ruim isso que você está dizendo, mas em mim gera esse tipo de reação, você já viu isso outras vezes [nas suas interações com outras pessoas]? Como você se sente ao perceber que isso causa esse tipo de impacto em mim? (T5).

\section{Ajudar o cliente a acessar novas perspectivas (sobre o outro e sobre si)}

Ao falar o que sente, terapeutas promovem no cliente a habilidade de tomada de perspectiva reflexiva da vivência do outro. Tornar acessível sua perspectiva sobre o que foi dito ou demonstrado pelo cliente pode ampliar a forma dele enxergar o outro e a relevância do mundo interior da pessoa com quem se relaciona: "O paciente entender que ele não está sozinho, entender [longa pausa] que algumas emoções são minhas, não dele" (T6).
O que a gente vê no consultório, é que os pacientes acham que [...] que ninguém tem o mesmo sofrimento que ele. E quando eles encontram outras pessoas com vivências similares, quando encontram que às vezes o sentimento é até igual, o processo de cura, no que eu percebo, se dá até mais rápido ( $\mathrm{T} 14)$.

O terapeuta que manifesta seu sentimento em resposta ao que foi trazido pelo cliente, ajuda também numa tomada de perspectiva contextual da própria experiência do cliente na interação. A conversação sobre a reação do terapeuta frente ao que o cliente está vivendo, ajuda a ver que emoções fazem parte de histórias. Ajuda o cliente a desenvolver uma leitura do que ele sente e dos motivos desses sentimentos no contexto interpessoal:

É para mostrar algo que possivelmente aquela pessoa não está percebendo ou está minimizando. Muitas vezes as pessoas [...], estão contando uma história como se fossem pontos desassociados, são situações que a pessoa não consegue nomear. E aí nessas situações geralmente [...] eu falo (T10).

\section{Propor modelos para novos comportamentos}

A exposição de emoções do terapeuta pode ajudar o cliente a inovar suas estratégias de vida. Pode oferecer uma alternativa de caminho para o cliente: "Ajuda o cliente porque tá dando um modelo de relação que pode funcionar e ser aberta, onde as pessoas podem se colocar vulneráveis e não serem punidas por isso" (T1). A relação estabelecida entre terapeuta e cliente pode servir como inspiração para que outras relações, em outros contextos, também possam mudar:

Eu quero gritar também, devolver na mesma intensidade que o cliente trouxe. Mas não grito, porque minha intenção é dar um modelo, mostrar que sentimentos inclusive os negativos, podem ser expressos de outra forma, que não seja a agressiva. Honesta, sincera, mas sem agressividade (T8). 


\section{Consequências pessoais e profissionais para o terapeuta}

Dar abertura para o trabalho com suas próprias emoções traz repercussões para o terapeuta. Para alguns trouxe uma nova perspectiva sobre si ou sobre algum aspecto da vida para além da profissão. Identificaram benefícios enquanto pessoa e aprendizados que podem ser úteis em outros papéis sociais que exercem. $\mathrm{O}$ uso dos seus sentimentos como recurso de trabalho tende a promover o autoconhecimento: "Estar envolvido mesmo! E cada pessoa que traz algo numa relação tá mostrando coisas pra gente e da gente que a gente precisa também olhar e trabalhar e aceitar que a gente também tem o lado sombra" (T3). Usar suas emoções na sessão oportuniza ao profissional revisitar seus valores pessoais "Foco sempre no meu desenvolvimento como pessoa, trabalhar com minha vulnerabilidade, assertividade, coisas que me valem mais do que como profissional né? Me valem como gente mesmo" (T8).

Outros benefícios dizem respeito diretamente à vida profissional. Alguns participantes atribuíram aprimoramentos em sua capacitação ao trabalho com suas emoções na sessão, como uma maior flexibilidade e sensibilidade advinda da própria experiência de tornar-se vulnerável na relação: "Acho que com essa prática, você vai perdendo esses medos de errar dentro do processo e você vai vendo que tem que estar aberto a isso também" (T2).

Ganho como terapeuta pelo processo autorreflexivo, por ir tomando conta, em algumas situações que não sou dona do saber. O quanto é importante desenvolver essa humildade e esse autoconhecimento mesmo, que isso vai ter impacto direto sobre o meu trabalho (T11).

\section{Discussão}

O presente estudo foi antecipado por outros realizados na mesma linha de pesquisa. A partir de um estudo de caso, Machado eVandenberghe (2014) argumentaram que, ao incluir a vivência subjetiva do terapeuta na sessão, torna-se possível aprofundar o trabalho com as dimensões emocional e interpessoal da psicoterapia e introduzir estratégias mais vivenciais, evitando que o processo terapêutico fique excessivamente no nível racional. Vieira e Vandenberghe (2017) descrevem como terapeutas desvelam informações pessoais sobre si na sessão e em quais situações as evitam. Esse estudo já mostrou que as intenções dos profissionais, ao falar de si, são ligadas a objetivos que beneficiam o processo terapêutico. Os participantes consideraram como deslizes as vezes que falaram de si para algum benefício próprio, por exemplo para justificar algum atraso ou envaidecer-se. O mesmo estudo mostrou também que os terapeutas que decidem não se expor, tomam essa decisão para evitar que o processo terapêutico seja prejudicado (perda de foco do processo, gerar más interpretações, contaminar o vínculo) ou pelo desejo do profissional de se proteger das consequências aversivas da exposição.

A contribuição do presente artigo a essa linha de pesquisa foi de operacionalizar os objetivos e as consequências da manifestação emocional do terapeuta. As intenções dos terapeutas ao manifestarem suas emoções são não só terapêuticas, mas também diagnósticas, envolvendo até a possibilidade de afinar a conceituação do caso. As consequências, por sua vez, para a pessoa do terapeuta envolvem crescimento pessoal e profissional, sugerindo que os profissionais que evitam abrir-se para evitar impactos aversivos acabam abrindo mão de oportunidades de crescimento profissional e pessoal.

Oliveira e Vandenberghe (2009) focam nas dificuldades da relação terapêutica, no sofrimento que a relação pode gerar no terapeuta e em como esse sofrimento pode beneficiar o processo terapêutico. Silvestre e Vandenberghe (2014) examinaram como emoções positivas são geradas no terapeuta pela interação terapêutica e como essas emoções, por sua vez influenciam o processo clínico e a experiência dos seus participantes. $\mathrm{O}$ presente estudo abarca tanto emoções positivas quanto negativas, porém é mais específico por buscar o sentido que há em trabalhar ativamente alguma resposta pessoal do terapeuta com um cliente.

Por outro lado, o estudo atual consegue dialogar com estudos mais antigos quando identifica que falar sobre as emoções do terapeuta pode ajudar o cliente a compreender sua vivência como legítima ou natural, validar a realidade do cliente, aumentar a similaridade percebida entre terapeuta e cliente, modelar ou sugerir formas adequadas de pensar e agir (Edwards, \& Murdock, 1994; Geller, \& Farber, 1997; Goldfried et al. 2003; Knox, Hess, Petersen, \& Hill, 1997). A essa literatura, o presente estudo acrescenta 
uma operacionalização mais extensa desse conteúdo e agrega categorias antes não abarcadas.

A formação do terapeuta reside na capacitação de habilidades e na supervisão (Hill, \& Lent, 2006). Mas há evidências que, com o que vivenciam com seus clientes, terapeutas aprendem muito sobre terapia (Farber, 1983; Freeman, \& Hayes, 2002; Orlinsky, Botermans, \& Ronnestad, 2001; Ronnestad, \& Skovholt, 2003; Skovholt, \& McCarthy, 1988), sobre si mesmos e sobre suas próprias questões (Farber, 1983; Jodry, 2003; Masi, 2003). O presente estudo acrescenta a especificação de que o trabalho com as emoções do terapeuta na sessão pode ser o motor desses benefícios incidentais, mas importantes para o profissional. Lidos nesse contexto, os resultados confirmam que a terapia é um processo de mão dupla, em que terapeuta e cliente se abrem a mudança. É essa proximidade emocional que possui a capacidade para transformação.

Linehan (1988) já descreveu a relação terapêutica como um processo interpessoal no qual o terapeuta e o cliente permutam influências recíprocas, enriquecendo a vida de ambos. A contribuição da pesquisa atual é que esse processo se potencializa quando o terapeuta se arrisca a manifestar suas emoções genuínas no relacionamento. Trata-se de uma prática que valoriza a autenticidade em que a atuação clínica está pautada, mais do que as questões técnicas da profissão.

\section{Considerações finais}

De acordo com o modelo geral construído nessa pesquisa, terapeutas só optam por falar de si na sessão, quando esse ato tem algum objetivo clínico específico. Um leque de motivos clínicos leva os profissionais a manifestar suas emoções na sessão. Essas emoções servem como recurso para diagnóstico e acesso aos problemas do cliente, auxiliam o terapeuta a compreender e formular melhor o caso, além de servir para intervenções (evocar ou reforçar comportamentos alvo e enfraquecer comportamento problema). Terapeutas expressam o que sentem para que o cliente tenha acesso a perspectivas alternativas, desenvolva consciência da perspectiva do outro e uma compreensão contextual da própria experiência na interação. Essa abertura pode ainda sustentar interpretações relacionais e introdução de modelos para novas estratégias interpessoais.
Ao usar o que sente na sessão, o terapeuta passa a ser sua própria ferramenta de trabalho. Nesse processo, como efeito colateral da atuação, o terapeuta é também transformado, pois aprende e tem oportunidade de ressignificar questões de sua vida e da sua atuação. Chama a atenção que os participantes do estudo tipicamente se pautaram na apreciação pontual da relevância da emoção para os objetivos terapêuticos - e raramente em regras explícitas para decidir quando e como utilizar suas emoções. Isso indica um trabalho muito mais intuitivo que sistematizado e mais baseado na experiência do que na teoria.

As limitações do estudo incluem um pequeno grupo de participantes, de tal forma que não permite generalizações. Uma preocupação em trabalhos baseados nos preceitos da Grounded Theory Analysis, é que a metodologia envolve a interpretação pelo pesquisador, havendo a possibilidade de vieses. Relacionado à metodologia de entrevistas livres, é sempre possível que os participantes destorçam uma pergunta ou omitam algum dado que poderia contribuir com a pesquisa. O método usado não permite quantificar as emoções referidas, almejando só compreender o sentido delas na atuação clínica dos participantes.

A expectativa do presente trabalho é ampliar o acesso à sabedoria prática dos terapeutas no campo a respeito dos objetivos que terapeutas possuem ao manifestar suas emoções e as consequências advindas dessas exposições. O presente artigo pretende acrescentar às regras já conhecidas baseadas em diretivas teóricas, uma interpretação a partir da visão dos profissionais clínicos. Todavia pode-se pensar na necessidade de desenvolver uma discussão ampla sobre as práticas reais que envolvem as emoções do terapeuta como recurso terapêutico. As contribuições presentes nesse estudo situam-se nesse ponto.

Espera-se que estudos semelhantes, tanto qualitativos quanto quantitativos passem a ser realizados, com o intuito de verificar se este uso das emoções do terapeuta de fato contribui para melhores resultados na terapia. Novas investigações podem abranger o processo e os resultados em psicoterapias a partir deste ângulo. 


\section{Referências}

Blumer, H. (1969). Symbolic interactionism. Englewood Cliffs, NJ: Prentice Hall.

Charmaz, K. (2006). Constructing grounded theory: A practical guide through qualitative analysis. Thousands Oaks, CA: Sage.

Cunha, O. R., \& Vandenberghe, L. (2016). O relacionamento terapeuta-cliente e o transtorno de personalidade borderline. Revista Brasileira de Terapia Comportamental e Cognitiva, 8(1), 72-86. https://doi. org/10.31505/rbtcc.v18i1.833

Edwards, C. E., \& Murdock, N. L. (1994). Characteristics of therapist self-disclosure in the counseling process. Journal of Counseling and Development, 72(4), 358-389. https://doi.org/10.1002/j.1556-6676.1994.tb00954.x

Farber, B. A. (1983). Introduction: A critical perspective on burnout. In: B. A. Farber (Ed.), Stress and burnout in the human services professions (p. 1-20). Nova York, NY: Pergamon.

Fideles, M.N. D., \& Vandenberghe, L. (2014). Psicoterapia analítica funcional feminista: Possibilidades de um encontro. Revista Psicologia: Teoria e Prática, 16(3), 18-29. http://dx.doi.org/10.15348/1980-6906/psicologia. v16n3p18-29

Freeman, M. S., \& Hayes, B. G. (2002). Clients changing counselors: An inspirational journey. Counseling and Values, $47,13-21$.

Geller, J. D., \& Farber, B. A. (1997). Why therapists do and don't disclose. Paper presented at the Annual Meeting of the American Psychological Association. Chicago, IL.

Glaser, B. (1998). Doing grounded theory: Issues and discussion. Mill Valey, CA: Sociology Press.

Goldfried, M. R., Burckell, L. A., \& Eubanks-Carter, C. (2003). Therapist self-disclosure in cognitive-behavior therapy. Journal of Clinical Psychology, 59(5), 555-568. https://doi.org/10.1002/jclp.10159

Henwood, K., \& Pidgeon, N. (2003). Grounded theory in psychological research. In: P. M. Camic, J. E. Rhodes, \& L. Yardley (Orgs.), Qualitative research in psychology: Expanding perspectives in methodology and design (pp. 131-155). Washington, DC: American Psychological Association.

Hill, C. E., Helms, J. E., Tichenor, V., Spiegel, S. B., O’Grady, K. E., \& Perry, E. S. (1988). Effects of therapist response modes in brief psychotherapy. Journal of Counseling Psychology, 35, 222-233. https://doi.org/10.1037/00220167.35.3.222

Hill, C. E., \& Lent, R. W. (2006). A narrative and meta-analytic review of helping skills training: Time to revive a dormant area of inquiry. Psychotherapy: Theory, Research, Practice, Training, 43(2), 154-172. https://doi. org/10.1037/0033-3204.43.2.154

Jodry, J. (2003). From patient to client to fellow traveler: How psychotherapists grow through their interactions in the therapeutic relationship. Dissertation Abstracts International: Section B: The Sciences and Engineering, 64(4B), 1680.

Knox, S., Hess, S. A., Petersen, D. A., \& Hill, C. E. (1997). A qualitative analysis of client perceptions of the effects of helpful therapist self-disclosure in long-term therapy. Journal of Counseling Psychology, 44(3), 274-283. https://doi.org/10.1037/0022-0167.44.3.274

Linehan, M. M. (1988). Perspectives on the interpersonal relationship in behavior therapy. Journal of Integrative and Eclectic Psychotherapy, 7(3), 278-290.

Lyn, R., \& Morse, J. M. (2013). Read me first for a user's guide to qualitative methods. Los Angeles, CA: Sage.

Machado, A. A. C., \& Vandenberghe L. (2014). Relação terapêutica na terapia cognitivo comportamental: Desafios e possibilidades com uma paciente borderline. Psychologica, 57(2), 95-109.

Masi, G. (2003). Phenomenology and comorbidity of dysthymic disorder in 100 consecutively referred children and adolescents: Beyond DSM-IV. Canadian Journal of Psychiatry, 48(2), 99-105. https://doi. org/10.1177/070674370304800206

Oliveira, J. A., \& Vandenberghe, L. (2009). Upsetting experiences for the therapist in-session: How they can be dealt with and what they are good for. Journal of Psychoterapy Integration, 19(3), 231-245. http://dx.doi. org/10.1037/a0017070 
Orlinsky, D. E., Botermans, J. F. \& Ronnestad, M. H. (2001). Towards an empirically-grounded model of psychotherapy training: four thousand therapists rate influences on their development. Australian Psychologist, 36(2), 139148. https://doi.org/10.1080/00050060108259646

Ronnestad, M. H., \& Skovholt, T. M. (2003). The journey of the counselor and therapist: Research findings and perspectives on development. Journal of Career Development, 30(1), 5-44. https://doi. org/10.1177/089484530303000102

Santo, R. A. D., \& Vandenberghe, L. (2015). Campo e função dos sentimentos da terapeuta na relação terapêutica. Contextos Clínicos, 8(2), 193-200. https://doi.org/10.4013/ctc.2015.82.08

Silvestre, R. L. S., \& Vandenberghe, L. (2008). The therapist's feelings. International Journal of Behavioral Consultation \& Therapy, 4(4), 355-359.

Silvestre, R. L. S., \& Vandenberghe, L. (2014). Therapists' positive emotions in-session: Why they happen and what they are good for. Counselling and Psychotherapy Research, 14(2), 119-127. https://doi.org/10.1080/14 733145.2013.790455

Skovholt, T. M., \& McCarthy, P. (1988). Critical incidents: Catalysts in counselor development. Journal of Counseling and Development, 67(2), 69-73. https://doi.org/10.1002/j.1556-6676.1988.tb02016.x

Tsai, M., Kohlenberg, R. J., Kanter, J. W., Holman, G. I., \& Loudon, M. P. (2012). Functional analytic psychotherapy: Distinctive features. Hove: Routledge.

Vandenberghe, L., Coppede, A. M. \& Kohlenberg, R. J. (2006). Client curiosity about the therapist's private life: Hindrance or therapeutic aid? The Behavior Therapist, 29(3), 41-46.

Vandenberghe, L., Nasser, K. C. F. O., \& Silva, D. P. (2010). Couples therapy, female orgasmic disorder and the therapist-client relationship: Two case studies in functional analytic psychotherapy. Counselling Psychology Quarterly, 23(1), 45-53. https://doi.org/10.1080/09515071003665155

Vandenberghe, L., \& Silveira, J.M. (2013). Therapist Self-as-Context and the curative relationship. Journal of Contemporary Psychotherapy, 43(3), 159-167. https://doi.org/10.1007/s10879-012-9230-8

Vieira, M. F. J. A., \& Vandenberghe, L. (2017). O self do terapeuta na terapia comportamental. In: L. E. G. Nalini (Org.), Teoria, pesquisa e aplicação em psicologia: Processos comportamentais (pp. 77-90). Curitiba, PR: Apris.

Olívia Rodrigues da Cunha

Doutoranda em Psicologia pela Pontifícia Universidade Católica de Goiás, Goiânia - GO. Brasil.

E-mail: olivia.rcunha@gmail.com

(iD) https:// orcid.org/0000-0001-7663-7532

Luc Vandenberghe

Doutor em Psicologia pela Université de l'Etat à Liège, Bélgica. Professor na Pontifícia Universidade Católica de Goiás, Goiânia - GO. Brasil.

E-mail: luc.m.vandenberghe@gmail.com

(iD https:// orcid.org/0000-0003-3252-3351

Endereço para envio de correspondência:

Rua 9-A, no164/1108, Setor Oeste 74110-110

Goiânia - GO. Brasil.

Recebido 04/04/2017

Reformulado 18/06/2018

Aceito 17/09/2018 
Psicologia: Ciência e Profissão 2019, 39, e178057, 1-12.

Received 04/04/2017

Reformulated $06 / 18 / 2018$

Approved 09/17/2018

Recibido 04/04/2017

Reformulado 18/06/2018

Acceptado 17/09/2018

Como citar: Cunha, O. R., \& Vandenberghe, L. (2019). Manifestações emocionais do terapeuta durante as sessões: Por que arriscar-se e quais benefícios esperar?. Psicologia: Ciência e Profissão, 39, 1-12.

https://doi.org/10.1590/1982-3703003178057

How to cite: Cunha, O. R., \& Vandenberghe, L. (2019). Emotional manifestations of the therapist during sessions: Why take risks and what benefits to expect?. Psicologia: Ciência e Profissão, 39, 1-12. https://doi.org/10.1590/1982-3703003178057

Cómo citar: Cunha, O. R., \& Vandenberghe, L. (2019). Manifestaciones emocionales del terapeuta durante las sesiones: ¿Por qué arriesgarse y qué beneficios esperar?. Psicologia: Ciência e Profissão, 39, 1-12. https://doi.org/10.1590/1982-3703003178057 